\title{
An evaluation of the automated assay of urinary oestrogens in pregnant women
}

The Late G. G. MUiR, M. RYAN, AND D. U. CONAILl

From the Department of Pathology, Luton and Dunstable Hospital, Luton, Beds.

SYNOPSIS An automated assay suitable for estimating urinary oestrogens in pregnanf women has been investigated. Fluorimetry was found to have considerable advantages ove colorimetry. The fluorimetric assay was simpler, more precise, more sensitive, and eliminate $₫$ the need for correction for non-specific chromogens; in the assay of oestriol in pregnan women there was no need for correction for non-specific fluorescence. Spectrofluorimetric and photometric analyses, recoveries, and reproducibility show that the method offers a robuș means of providing values for urinary oestrogen in pregnant women on a scale of up to $10 \%$ tests a day, the time of the assay being one and a half hours.

Conaill and Muir (1967 and 1968) developed an automated assay for total oestrogens in pregnancy in which the Allen correction for non-specific chromogens was replaced by that of Fournier, Shields, Neil, Hayes, and Papineau-Couture (1966). Spectral studies of the effluent obtained during steady-state analysis suggested that this correction was justified. Brown, Mcnaughtan, Smith, and Smyth (1968) published a study of the estimation of oestrogens by the Kober colour reaction (Kober, 1931) coupled with the Ittrich extraction (Ittrich, 1958) using both colorimetry and fluorimetry. These workers found that at $120^{\circ} \mathrm{C}$ the Kober colour complex could be developed in five minutes and that a simple factor could be used to correct for non-specific fluorescence. We have repeated our original spectral studies and carried out spectrofluorimetric studies based on Brown's original observations. It was hoped that the use of fluorimetry would eliminate the need for two colorimeters and simplify the automated system.

\section{Methods}

Figure 1 shows the manifold used to compare Received for publication 15 October 1969. colorimetry and fluorimetry; for either the fluorimetric or colorimetric methods the othes instruments were bypassed. Where necessary urine samples were made up to a 24-hour volume of $1,500 \mathrm{ml}$. Five $\mathrm{ml}$ of diluted urine was hydre lysed with $5 \mathrm{ml}$ of $50 \%$ hydrochloric acid at $100^{\circ} \mathrm{C}$ for one hour. After hydrolysis, the samples were placed in $8 \mathrm{ml}$ AutoAnalyzer cups and sampled at 20. samples per hour, with a sample:wash ratio of $1:$ ? The samples were segmented with ether, passed through two double mixing coils, after which the phases were separated. The ether phase was thed segmented with saturated quinol in $50 \%$ suE phuric acid and entered the digestor; during if passage down the digestor the ether was evapo orated off and the Kober colour was develope The first heater was set at $100^{\circ}$ and the secong ${ }^{\circ}$ heater at $180^{\circ}$; the motor gears were set at 6 rpm At the end of the digestor coil, the Kober conf plex was diluted with water and then segmenteg with paranitrophenol in chloroform. After the extraction in a pair of double mixing coils the phases were separated and the chloroform phas was passed into the flow cells of the two color ? meters and thence to the fluorimeter. The $540 \mathrm{ma}$ colorimeter had a light path of $15 \mathrm{~mm}$ while the $420 \mathrm{~m} \mu$ had a light path of $8 \mathrm{~mm}$. A mercury aro with a $535 \mathrm{~m} \mu$ Balzar interference filter, providea the primary light source, and the monochromator. 


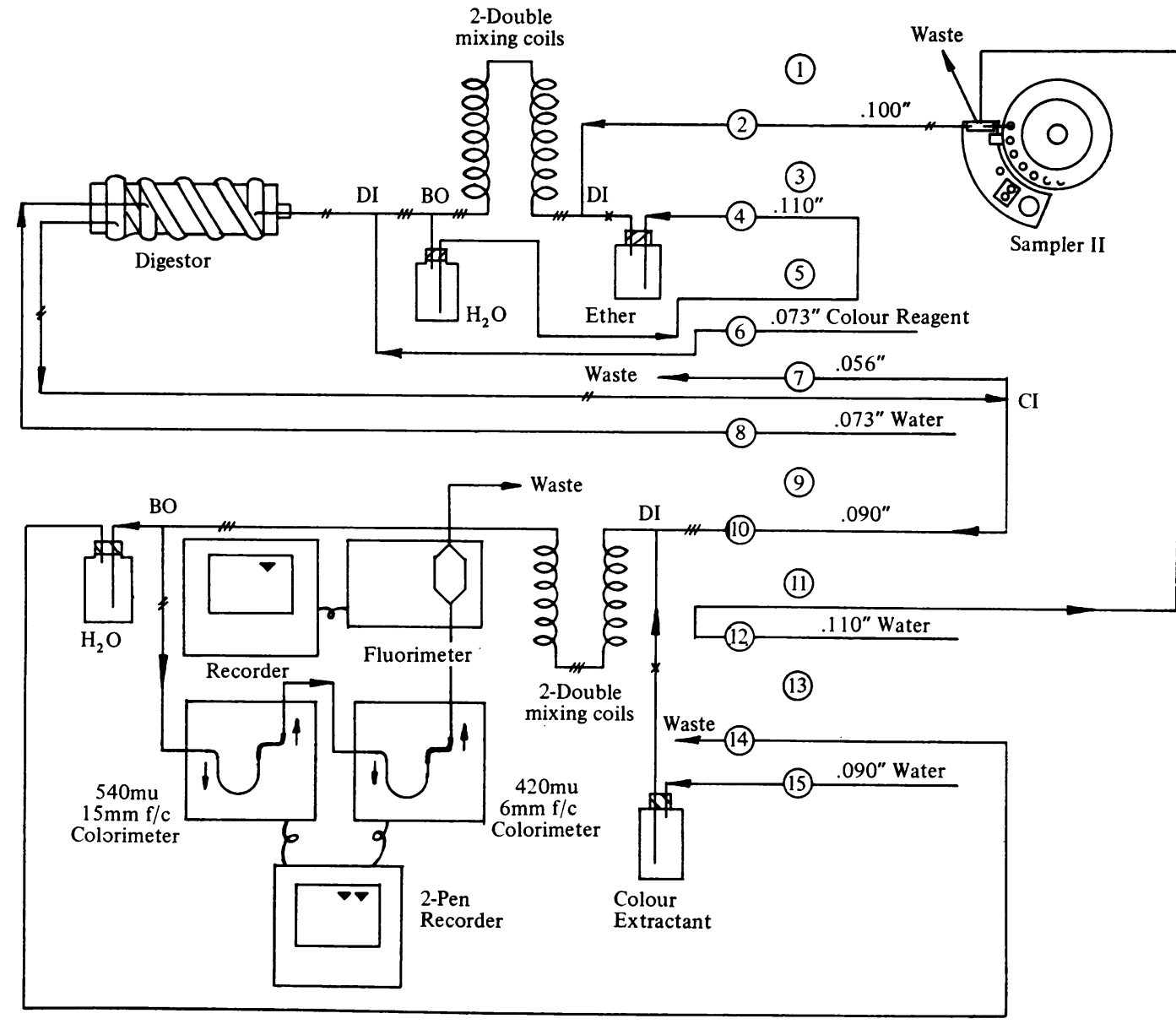

Fig. 1 The manifold used for urinary oestrogen assays by ether and/or colorimetry.

on the secondary side was set to read at $555 \mathrm{~m} \mu$. The voltage control of the fluorimeter was set at half voltage with the course control set at 3 o'clock. The instrument was more stable when the day-to-day adjustments were made with the Iris diaphragm, which was adjusted so that an oestriol standard of $15 \mathrm{mg} / \mathrm{l}$ gave an $80 \%$ deflection on the recorder. The ether and chloroform reagents were pumped by a displacement bottle technique.

\section{Reagents}

All reagents were of Analar grade unless stated otherwise.

\section{DIETHYL ETHER}

\section{Colour reagent}

This wa: saturated quinol in $50 \%$ sulphuric acid.
To $15 \mathrm{~g}$ of quinol in a 2-litre flask, $500 \mathrm{ml}$ distilled water was added. The flask was cooled in a water bath and the contents were stirred continuously while $500 \mathrm{ml}$ of concentrated sulphuric acid was added. The solution was then stood overnight and any crystals formed were removed by filtration the following day. The reagent was stored in a dark bottle.

\section{Colour extractant}

This consisted of $2 \%(\mathrm{w} / \mathrm{v})$ paranitrophenol in chloroform.

\section{Stock standard}

Oestriol in ethanol, $1 \mathrm{mg}$ per $\mathrm{ml}$.

Working standards

Of the stock solution, $0.25,0.5,0.75,1.0,1.25$, and $1.5 \mathrm{ml}$ solution were diluted to $100 \mathrm{ml}$ with distilled water. These represented oestriol concentrations of $2 \cdot 5,5 \cdot 0,7 \cdot 5,10 \cdot 0,12 \cdot 5$, and 15.0 mg of oestriol per litre. 


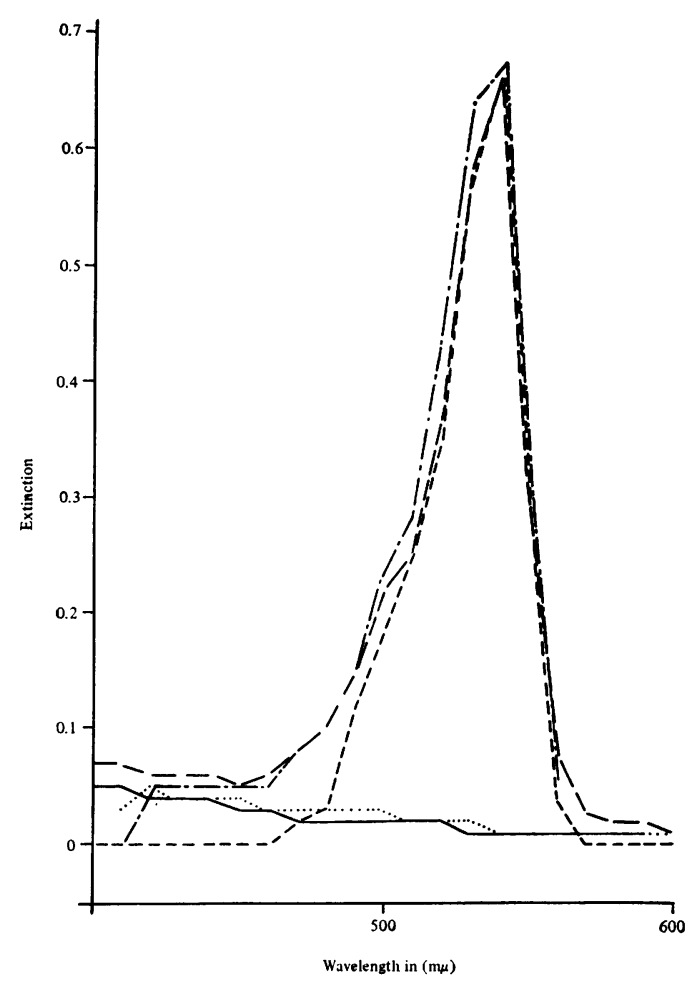

Fig. 2 Extinction spectra obtained on the products of the automated Kober reaction. Pools of various urines were assayed at steady state. Urine pools from males - ; urine pools from non-pregnant females .......; urine pools from pregnant women ; urine pools from males to which oestriol had been added to concentration of $20 \mathrm{mg}$ per litre - - - - ; pure oestriol standard - - - -

\section{Equipment}

Standard Technicon equipment was used throughout, with the exception of the modification to the digestor to alter the direction of the air flow and trap the evaporated ether (Conaill and Muir, 1968). A Locarte fluorimeter (model number MK 5) with a flow cell attachment and a recorder box was used.

\section{Results}

STUDIES ON THE COLORIMETRIC METHOD

\section{Specificity}

Several pools of urine from pregnant women were hydrolysed and each was sampled continuously until the recorder indicated that a steady state had been obtained. The products were then collected and $3 \mathrm{ml}$ was placed in a $10 \mathrm{~mm}$ light path silica cuvette. The extinction spectra of the

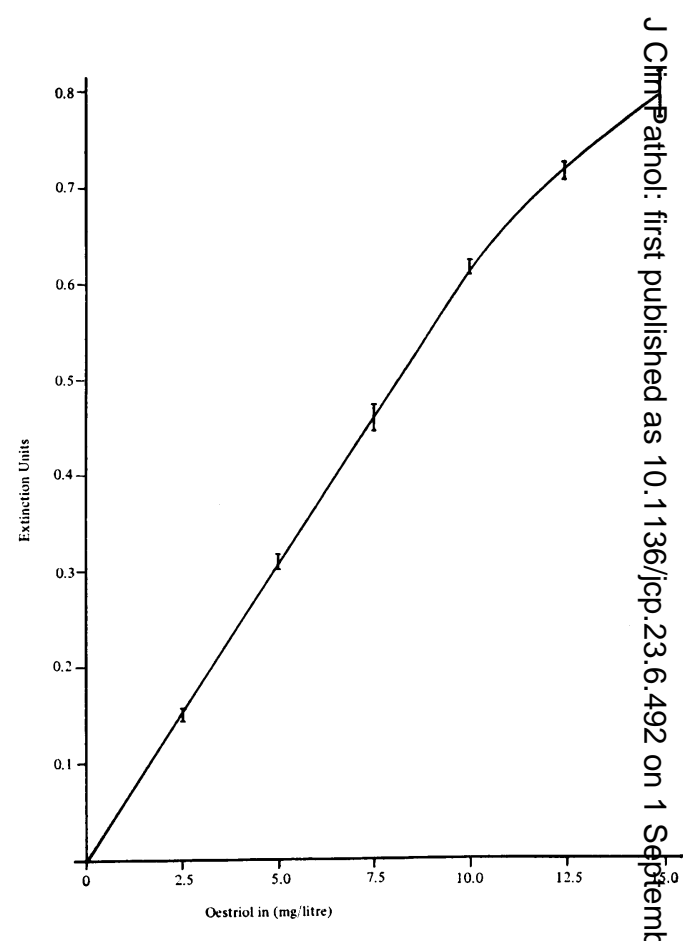

Fig. 3 The colorimetric standard curve showing the mean value plus or minus 1 standard deviation.

products were rapidly scanned at $10-\mathrm{m} \mu$ intervais from $400 \mathrm{~m} \mu$ to $600 \mathrm{~m} \mu$, using the Hilger Gilfo $\mathrm{d}$ spectrophotometer. The spectra of pure standargs pooled urines from non-pregnant women, poolegd male urines, and pooled male urines to whieh standard had been added are shown in Figure? The extinction spectra from pooled urines from pregnant women and that from pure standa added to male urine were similar.

The Fournier correction assumes that an ether extract of a urine, not containing oestrisgens, gives a spectrum due to non-speciffic chromagens which decreases linearly from 480 $\mathrm{m} \mu$ to $600 \mathrm{~m} \mu$ and that the extinction at $540 \mathrm{~m}$. is half that found at $420 \mathrm{~m} \mu$. We were able 90 confirm that in pools of male and female urine the decreases in extinction were linear. In the automated assay the $15 \mathrm{~mm}$ and $8 \mathrm{~mm}$ flow ceits are used and the optical extinction of a solution of haemoglobin in the $8 \mathrm{~mm}$ flow cell was her that found in the $15 \mathrm{~mm}$ flow cell.

\section{Linearity}

The working standards were processed in batches of ten. Figure 3 gives the mean extinctions afed the standard deviation plotted against oestriol concentrations. The curve appears to be linear to $10 \mathrm{mg}$ per litre.

\section{Precision}

The repeatability in a single batch was detêmined by measuring 10 aliquots of three differept urine samples from a pregnant woman. At the 


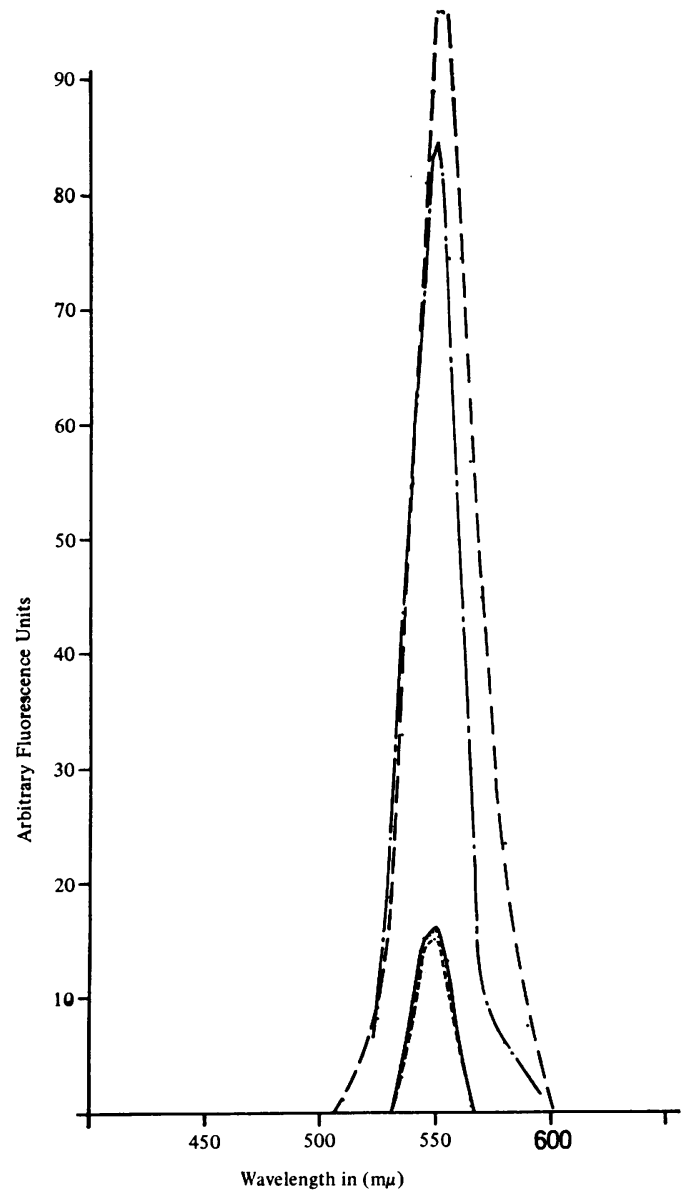

Fig. 4 Fluorescent emission spectra of the automated Kober complexes obtained at steady state analysis, with the fluorimeter set at the higher sensitivity. Diluted urine pools from pregnant women - oestriol standard $500 \mu \mathrm{g}$ per litre $-\ldots-\ldots$ reagent solvent mixture - urine pools from non-pregnant women - - ; urine pools from males ..........

mean value of $7 \cdot 3 \mathrm{mg}$ per litre the standard deviation was $0.2 \mathrm{mg}$, at $14.0 \mathrm{mg}$ per litre it was $0.9 \mathrm{mg}$, and at $24.6 \mathrm{mg}$ per litre it was $2.0 \mathrm{mg}$. Reproducibility between batches was determined. A 24-hour specimen was split into small aliquots which were deep frozen, and were used as controls over a period of three months. The mean concentration was $26.4 \mathrm{mg}$ per litre and the standard deviation $1.6 \mathrm{mg}$ per litre. Over a similar period of time, 83 specimens were estimated in duplicate; the mean result was $15 \cdot 1 \mathrm{mg}$ per litre and the standard deviation $0.86 \mathrm{mg}$ per litre.

\section{Correlation with the Manual Ittrich Method}

A series of 83 urines was estimated by the auto- mated and manual Ittrich method as modified by Cartlidge, Spencer, Swyer, and Woolf (1961). The coefficient of correlation was 0.83 which was significant at the $1 \%$ level.

\section{Studies on the Fluorimetric Method}

In the automated fluorimetric method, an aspirate of water, extraction solvents, and colour reagents provided the recorder base line. This base line was read continuously between the peaks, and this ensured that each sample was read against a reagent solvent blank.

Studies on the Specificity of the Fluorimetric
Method Spectrofluorimetric studies similar to those of $\vec{c}$ Brown et al (1968) were made of the Kober colour. $\mathbb{D}$ The apparatus was set to sample continuously $\frac{\mathbb{\Phi}}{\mathbb{D}}$ from pooled hydrolysed urines, standards, and $?$ water. The primary beam was set at $535 \mathrm{~m} \mu$ and $\mathbb{\triangle}$ the monochromator moved through the spectrum from $450 \mathrm{~m} \mu$ to $600 \mathrm{~m} \mu$. After each change of wavelength the recorder was allowed to settle before proceeding to the next. Emission spectra were obtained for pure standard solutions, reagent solvent blanks, and different pools of urine. By altering the iris diaphragm the fluorimeter sensitivity was adjusted so that the $500 \mu \mathrm{g} \stackrel{\mathbb{2}}{\varrho}$ oestriol per litre gave an $80 \%$ deflection on the $\overrightarrow{\overrightarrow{0}}$ recorder. The resulting spectra obtained at the higher sensitivity are given in Figure 4. At this sensitivity setting and under normal wavelengths pools of urine from males and nonpregnant females gave the same deflection as the reagent blank; thus the use of the reagent solvent blank is a sufficient correction for non-specific fluorescence at this level of sensitivity.

The blank spectra were made by following the blank reading on either side of the $555 \mathrm{~m} \mu$ wavelength until there was no reading on the recorder. At the higher sensitivity the reagent solvent blank had a peak at $550 \mathrm{~m} \mu$ as distinct from the oestrogen peak at $555 \mathrm{~m} \mu$. This appeared to move the oestriol peak to $550 \mathrm{~m} \mu$, but in the difference spectra in the Table the peak was at $555 \mathrm{~m} \mu$.

\section{Correlation with the Colorimetric Method}

In Fig. 5 the upper tracings show the colorimetric results on a two-pen recorder, while the lower tracing shows the simultaneous fluorimetric results recorded on a single-pen recorder. Each set of results shows a standard curve followed by total oestrogen assays on urines from pregnant women, a carryover experiment, the results in 
The late G. G. Muir, M. Ryan, and D. U. Conaill
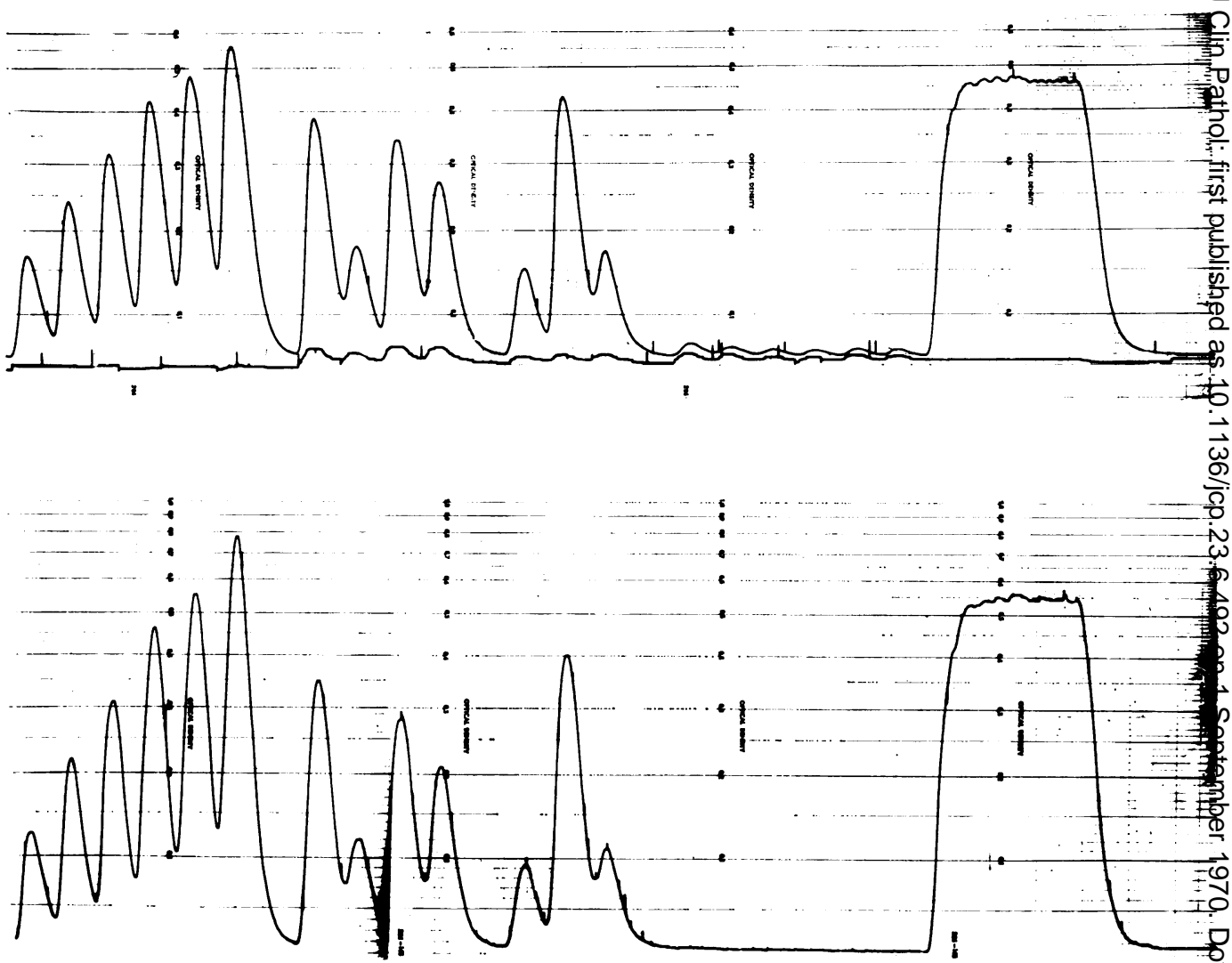

Fig. 5 The $540 \mathrm{m \mu}$ and $420 \mathrm{m \mu}$ colorimeter output are in the upper recorder chart while the lower demonstrates the fluorimeter output. These charts demonstrate serially six standards from 2.5 to $15 \mathrm{mg}$ oestriol per litre, assay peaks from urines from pregnant women, a carryover experiment in which the first and third samples are the same, assays on urine from non-pregnant women, and finally the assay run at continuous sampling.

\begin{tabular}{|c|c|c|c|c|c|c|c|}
\hline \multirow{2}{*}{$\begin{array}{l}\text { Wavelengt } \\
(\mu m)\end{array}$} & \multirow{2}{*}{$\begin{array}{l}\text { Standard } \\
\text { Solution }\end{array}$} & \multirow{2}{*}{$\begin{array}{l}\text { Urine from } \\
\text { Pregnant } \\
\text { Women }\end{array}$} & \multirow{2}{*}{$\begin{array}{l}\text { Urine } \\
\text { from Non- } \\
\text { pregnant } \\
\text { Women }\end{array}$} & \multirow{2}{*}{$\begin{array}{l}\text { Urine } \\
\text { from } \\
\text { Males }\end{array}$} & \multirow[t]{2}{*}{ Blank } & \multicolumn{2}{|c|}{ Difference Spectra } \\
\hline & & & & & & $\begin{array}{l}\text { Pregnant } \\
\text { Urine } \\
\text { Reading } \\
\text { Minus } \\
\text { Blank } \\
\text { Reading }\end{array}$ & $\begin{array}{l}\text { Standard } \\
\text { Reading } \\
\text { Minus } \\
\text { Blank } \\
\text { Reading }\end{array}$ \\
\hline 500 & - & - & - & - & - & - & - \\
\hline 510 & - & - & - & - & - & - & - \\
\hline 520 & - & - & - & - & - & - & - \\
\hline 525 & 8 & 9 & - & - & - & 9 & 8 \\
\hline 530 & 25 & $18 \cdot 5$ & - & - & - & 18.5 & 25 \\
\hline 535 & 37 & 33 & 3.0 & $3 \cdot 5$ & 4 & $29 \cdot 0$ & 33 \\
\hline 540 & 55 & 55 & $8 \cdot 5$ & 9 & $9 \cdot 5$ & $44 \cdot 5$ & 44.5 \\
\hline 545 & 75 & $81 \cdot 5$ & 14 & 14 & 15 & 60 & 60 \\
\hline 550 & 85 & $96 \cdot 5$ & 15 & 15 & 16 & $79 \cdot 5$ & 69 \\
\hline 555 & 75 & 93 & 11 & 12 & 13 & 80 & 62 \\
\hline 560 & 50 & 75 & 6 & $6 \cdot 5$ & 6 & 69 & 44 \\
\hline 565 & 30 & 57 & 0.5 & 1.0 & 1 & 56 & 29 \\
\hline 570 & 9 & 45 & - & - & - & 45 & 9 \\
\hline 580 & 6 & $23 \cdot 5$ & - & - & - & $23 \cdot 5$ & 6 \\
\hline 590 & - & $7 \cdot 5$ & - & - & - & $7 \cdot 5$ & - \\
\hline 600 & - & - & - & - & - & - & - \\
\hline
\end{tabular}

Table Results of spectrofluorimetric studies of the Kober chromogen developed using the automated procedure ${ }^{1}$

${ }^{1}$ Readings in arbitrary fluorescence units

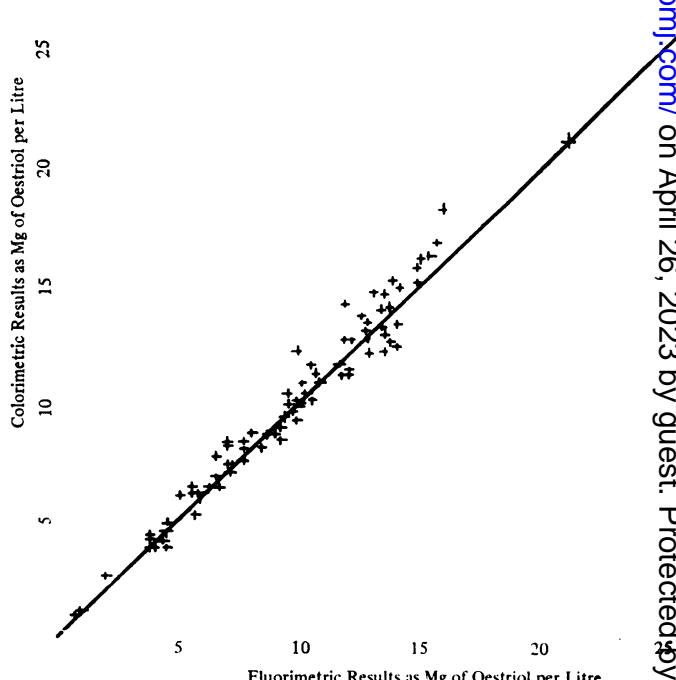

Fig. 6100 urine samples from pregnant women estimated by colorimetry and fluorimetry. 


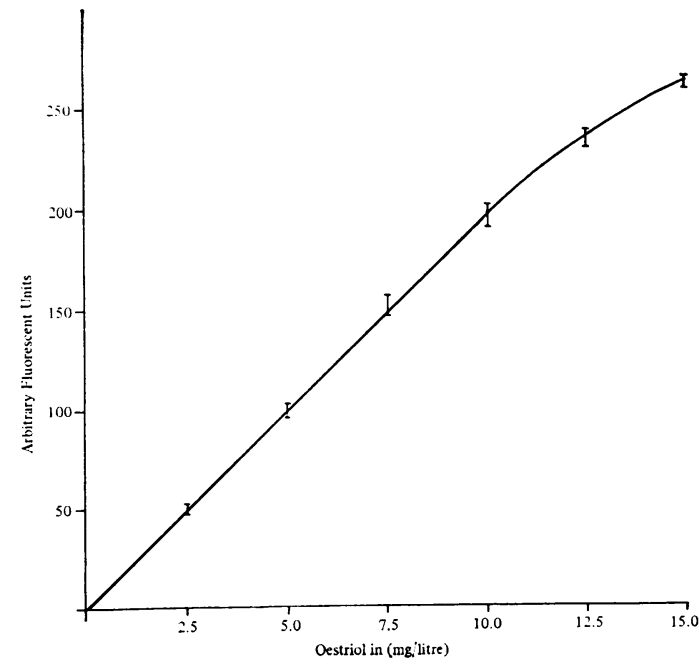

Fig. 7 Standard curve for fluorimetric method. The mean of six estimations plotted for each point with the 1 standard deviation range.

urines from non-pregnant women, and finally the results of continuous sampling. The carryover from a high to a low sample was calculated to be $5.5 \%$ of the high peak for both the colorimetric and fluorimetric systems. Urines from nonpregnant women gave no deflection. In Fig. 6 is shown a plot of 100 samples estimated by both systems. The coefficient of correlation for this set of results was $\mathbf{0 \cdot 9 8}$.

\section{Recovery of Added Oestriol}

The mean recovery of oestriol added before hydrolysis was found to be $75 \%$ with a standard deviation of $5.8 \%(n=15)$, and that of oestriol added after hydrolysis was $95.3 \%$ with a standard deviation of $4.6 \%(n=15)$. These recoveries were used as routine quality controls.

\section{Linearity of the Method}

The standards were estimated in batches of six; in Fig. 7, mean values and their standard deviations are plotted against oestriol concentrations. The standard curve is linear to $10 \mathrm{mg}$ per litre at the sensitivity used in the routine assay.

\section{Reproducibility of the Fluorimetric Method}

The repeatability within the batch was assayed at three levels, namely, $4.3 \mathrm{mg}$ per litre, $9.0 \mathrm{mg}$ per litre, $27.5 \mathrm{mg}$ per litre; 12 assays were done at each level. At these mean values the standard $\frac{\Omega}{\bar{F}}$ deviations were $0.21 \mathrm{mg}, 0.22 \mathrm{mg}$, and $0.79 \mathrm{mg}$. 0 The reproducibility between batches was esti- $-\frac{0}{+}$ mated on 15 occasions, and the mean result was $\underline{\text { ㅇ }}$ $9.5 \mathrm{mg}$ per litre with a standard deviation of $\Rightarrow$ $0.41 \mathrm{mg}$. One hundred estimations were carried $\stackrel{\text { of }}{+}$ out in duplicate; the mean result was $11.18 \mathrm{mg}$ 들 per litre and the standard deviation $\pm 0.54 \mathrm{mg}$.

\section{Discussion}

Any new method of assay must fulfil criteria of $\vec{\omega}$ validity before it can be adopted in a laboratory, and applies particularly to a method which brings? a difficult hormone assay within the reach of area laboratories. The precision of the method wasio estimated at three levels and expressed as the $\overrightarrow{0}$ coefficient of variation; for the colorimetric ${ }^{N}$ method it was $2.7 \%, 6.4 \%$, and $8.0 \%$, while for the fluorimetric method it was $4.9 \%, 2.4 \%$, and $2.9 \%$. As the oestriol concentration increased,, $\mathbb{D}$ the colorimetric method lost precision, but this $\frac{\mathbb{\Phi}}{\circ}$ was not so with the fluorimetric method. At the 3 lowest level, $4.3 \mathrm{mg}$ per litre, the fluorimetric method appeared to lose precision. With the $\overrightarrow{\overrightarrow{0}}$ sensitivity setting of the fluorimeter used in the routine assay, it is not possible to read oestriol. concentrations to an accuracy greater than $0.2 \mathrm{mg}$. per litre, which would explain this apparent loss of precision. The colorimetric method had a coefficient of variation between batches of $6.1 \%$ at $\stackrel{\Xi}{\%}$ $26.4 \mathrm{mg}$ per litre, while the coefficient of variation $\stackrel{\mathbb{\perp}}{2}$ for the fluorimetric method was $4.3 \%$ at $9.5 \mathrm{mg} \overrightarrow{\vec{F}}$ per litre, which agrees well with the coefficient of $\frac{3}{3}$ variation of $4.8 \%$ by the method of duplicate analysis. Our coefficient of variation for the automated ureas using diacetyl monoxime within the batch was $1.6 \%$, while between the batches by? the method of duplicate analyses it was $2 \cdot 8 \%$. As this is a relatively simple analysis compared with the oestrogen analysis, we feel that the coefficients of variation for the fluorimetric analysis are good and offer an improvement over the use of colorimetry.

The sensitivity of fluorimetry is greater than that of colorimetry as it was possible to detect $N$ less than $500 \mu \mathrm{g}$ per litre but, with colorimetry, $N$ levels of less than $1 \mathrm{mg}$ per litre could not be reliably detected. The enhanced sensitivity of the $\omega$ fluorimetric methods is well established. Van Kessel, Seitzinger, Schreurs, and Versteg (1969) have used the increased sensitivity of the fluorimetric methods to automate an aqueous Kober $\stackrel{-}{-}$ reaction with a final Ittrich extraction. In their method non-specific fluorescence and the inter- $\frac{\mathbb{D}}{\mathbb{D}}$ ference of glucose have been overcome by the very great dilution permitted by fluorimetry.

The question of specificity and accuracy in oestriol assays is difficult, as the most reliable $ᄋ$ methods are those involving gas chromatography coupled with thin-layer chromatography and 
isotopically labelled internal standards, which are obviously beyond the scope of an area laboratory. In this case we have compared the results obtained with the manual Ittrich procedure as modified by Cartlidge et al (1961). The coefficient of correlation was 0.83 which was significant at the $1 \%$ level. The evidence which we have presented as to specificity is the similarity between the spectrophotometric and spectrofluorimetric analysis of pure standards, standards added to urine, and pregnancy urines containing large amounts of oestrogens. Støa and Thorsen (1962), although somewhat critical of spectrophotometric analysis as a criterion of chemical specificity, expressed the view that spectrofluorimetric analysis offered a useful method of chemical characterization. It is our view that the combination of results of spectral analyses and the recoveries of pure oestriol added to urine samples before and after hydrolysis offer some guide as to the specificity of the method.

Unlike van Kessel et al (1969), we have retained the ether extraction. The use of ether rather than air segmentation, suggested by Child and Caisey (1966), provides an efficient extraction procedure with recoveries of $95.3 \% \pm 4.6 \%$, nor does it cause any increased carryover between samples. The use of a fluorimeter rather than two colorimeters has more to recommend it than simple convenience. Not only is the method more precise, but it does not depend on the assumption that behaviour of non-specific chromogens is the same in every urine sample. The choice of $535 \mathrm{~m} \mu$ as the primary beam follows the studies of Scholler, Leymarie, Heron, and Jayle (1966) on the excitation of spectra of oestriol in chloroform. We have departed from their recommendations to read at $550 \mathrm{~m} \mu$, as on our instrument the emission maxima were at $555 \mathrm{~m} \mu$. Brown et al (1968) recommended a gap of 19 to $20 \mathrm{~m} \mu$ between the primary and secondary wavelengths in order to eliminate exciting light, which this setting has enabled us to do. Strickler, Wilson, and Grauer (1961) found that $75 \%$ of the fluorescence of oestriol in chloroform was contained in the wavelengths $545-559 \mathrm{~m} \mu$.

Like Brown et al (1968) we have found that the use of a higher temperature speeds the development of the Kober colour; a sample takes 3.5 minutes to traverse the digestor. Strickler et al (1961) and Brown et al (1968) point out that the Kober complexes deteriorate at room temperature, and that the time between developing the complex and the reading must be kept to a minimum. In continuous flow analysis the time interval between the development and dilution of the Kober complex is always constant and the samples can be read continually against the reagent solvent mixture.
Another aspect which must be considered the assessment of a new method is its practicability and the cost per assay. This method is a piece 5 of chemical engineering which has made a tedious and difficult assay within the reach of any area laboratory, provided that the capital, abofut $£ 3,000$, is available, and any technician, famigar with continuous flow analysis, can perfom oestrogen estimations at a rate of over 100 हè day and provide an individual result within one and a half hours. The cost of the individual asšy is approximately $1 \mathrm{~s} 8 \mathrm{~d}$, including chemicals amd technician's time, but excluding capital cost.

In conclusion, we regard the automated $\overrightarrow{a \vec{p}} \mathrm{~d}$ fluorimetric Ittrich assay as a robust assay which can estimate oestriol on a large scale in most açea laboratories.

It is a pleasure to acknowledge the receipt of a grant from the Research Committee of the North-West Metropolitan Regional Hospmal Board to enable us to purchase additiog gal equipment for this work.

References

Brown, J. B., Macnaughtan, C., Smith, M. A., and Smyth $\mathcal{C}_{B}$ (1968). Further observations on the Kober colour and Ittrich fluorescence reactions in the measurementof oestriol, oestrone and oestradiol. J. Endocr., 40, 175-\$88.

Cartlidge, K., Spencer, P. M., Swyer, G. I. M., and Woolf, (1961). Urinary oestriol determination of an indep of placental function. J. Endocr., 22, xvi-xvii.

Child, K., and Caisey, J. (1966). An automated method fordhe determination of urinary 17-hydroxy corticosteroids. In Proceedings of the Technicon Symposium, pp. 195Mediad, New York.

Conaill, D. U., and Muir, G. G. (1967). An automated method for the determination of oestrogens in pregnancy Automation in analytical chemistry, Technicon Symposim, vol. 2, pp. 137-142. Mediad, New York.

Conaill, D. U., and Muir, G. G. (1968). An automated me for the determination of estrogens in pregnancy. Qin. Chem., 14, 1010-1022.

Fournier, A., Shields, T. W., Neil, R. P., Hayes, C. M., Papineau-Couture, G. (1966). Automated determination of estrogens in the urine of pregnant mares. In Proceedongs of the Technicon Symposium, pp. 213-217. Mediad, Bew York.

Ittrich, G. (1958). Eine neue Methode zur chemischen Bestimm der östrogenen Hormone im Harn. Hopne-Seylers $Z$. physiol. Chem., 312, 1-14.

van Kessel, H., Seitzinger, R., Schreurs, J., and Versteg, G. (1969). Oestrogens in late pregnancy urine assayed by an aytomated fluorimetric procedure. Ned. T. Verlosk., 69, 81690.

Kober, S. (1931). Eine kolorimetrische Bestimmung des Brunsthormons (Menformon). Biochem. Z., 239, 210-212.

Scholler, R., Leymarie, P., Heron, M., and Jayle, M. F. (1966). A study of oestrogen fluorescence using Ittrich's procedute. Acta Endocr. (Kbh.), 52, Suppl. 107.

Støa, K. F., and Thorsen, T. (1962). Fluorimetric determination of oestrogenic steroids using Ittrich's extraction metfod. Acta Endocr. (Kbh.), 41, 481-493.

Strickler, H. S., Wilson, G. A., and Grauer, R. C. (1961) improved $p$-nitrophenol method for oestrogen determination employing a commercial fluorimeter. Anatyt. Biochem., 2, 486-496. 